\title{
Coal-derived humic acid for application in acid mine drainage (AMD) water treatment and electrochemical devices
}

\author{
Tonkeswar Das $^{1} \cdot$ Mousumi Bora $^{1} \cdot$ Joyshil Tamuly $^{1} \cdot$ Santhi Maria Benoy $^{1} \cdot$ \\ Bimala P. Baruah ${ }^{1} \cdot$ Prasenjit Saikia $^{1} \cdot$ Binoy K. Saikia ${ }^{1,2}$
}

Received: 15 January 2021/Revised: 15 March 2021/ Accepted: 13 May 2021 / Published online: 16 June 2021

(C) The Author(s) 2021

\begin{abstract}
In this research work, isolation of humic acid from coal of Northeastern region of India is reported. The study is also targeted for application of the coal-derived humic acid in acid mine drainage (AMD) water treatment and electrochemical devices. All the obtained results are compared with the standard humic acid and examined the formation of humic acid from the coal. The isolated coal-derived humic acid is found to be high degree of humifications and relatively stable up to about $200{ }^{\circ} \mathrm{C}$. The FTIR study indicates the formation of metal-humic acid complexes. On treatment with acidic water (AMD), the coal-derived humic acid was found to have the ability to remove toxic metal such as (in order) $\mathrm{Pb}>\mathrm{Cu}>$ $\mathrm{Zn}>\mathrm{Cd}$. In addition, the preliminary electrochemical properties of the isolated humic acid are also discussed in the paper. The specific capacitance of the isolated coal-derived humic acid via cyclic voltammetry and charge-discharge analysis is found to be $7 \mathrm{mF} / \mathrm{g}$ at scan rate $10 \mathrm{mV} / \mathrm{s}$ and $22 \mathrm{mF} / \mathrm{g}$ within the potential window $0.4 \mathrm{~V}$, respectively. The chargedischarge cycles are stable for more than 1000 cycles within the potential window $0.4 \mathrm{~V}$. This study will create a new pathway for the further research in this field.
\end{abstract}

Keywords Value addition of coal $\cdot$ Indian coal $\cdot$ Humic acid $\cdot$ AMD water treatment $\cdot$ Electrochemical devices

\section{Introduction}

Humic acid has received tremendous research attention due to its wide range of application in the field of electrochemical devices (Yin et al. 2014; Wasiński et al. 2014; Zhu et al. 2015), agriculture sectors (Janos and Kozler 1995), rubber industry, colour industry, veterinary science,

Publisher's Note Springer Nature remains neutral with regard to jurisdictional claims in published maps and institutional affiliations.

Tonkeswar Das

tonkeswardasbabu@gmail.com

$凶$ Binoy K. Saikia

bksaikia@neist.res.in

1 Coal and Energy Group, Materials Science and Technology Division, CSIR-North East Institute of Science and Technology, Jorhat 785006, India

2 Academy of Scientific and Innovative Research (AcSIR), Ghaziabad 201002, India human medicine, nanoscience (Erdogan et al. 2007; Niu et al. 2011; Zhou et al. 2011; Peng et al. 2012; Zhang et al. 2013; Tang et al. 2017), waste water treatment (Liu et al. 2008; Li et al. 2011; Jiang et al. 2014; Tang et al. 2014), and as a dispersant of ceramic powders (Souza and Braganca 2018). Humic acid can also be used as raw material for the synthesis of graphene oxide (Powell and Beall 2015; Duraia and Beall 2015a), humic acid-based humidity sensor (Duraia et al. 2015b). The humic acid was generally isolated from lignite and also from coal by some researchers (Tripathi et al. 2009; Das et al. 2015, 2017a, b; Tang et al. 2017; Wang et al. 2017; Xiao et al. 2018; Cheng et al. 2019). However, the physico-chemical properties and mass production of humic acid from different types of coal is dependent upon the rank and coalification process (Stevenson 1994; Kurkova et al. 2004).

Different methods such as oxidation followed by alkaline extraction (Erdogan et al. 2007), solid phase activation process (Tang et al. 2017), bioconversion (Xiao et al. 2018; Tripathi et al. 2009), KOH-hydrothermal process (Cheng 
et al. 2019), non-catalytic oxidation with oxygen (Dekker et al. 1990), oxidation using nitric acid (Rousa et al. 1994), alkaline extraction followed by acidic precipitation and membrane separation (Skhonde et al. 2006), oxidation with $\mathrm{H}_{2} \mathrm{O}_{2}$ and $\mathrm{KMnO}_{4}$ (Fong et al. 2007), and the method applied by the International Humic Substance Society (IHSS) (http://humic-substances.org) are used to isolate humic acid from coal.

The utilization of the low-quality coals to make valueadded products are increasing progressively among the carbon researchers and industries due to the sharp fall of good and high-quality coal around the world (Das et al. 2013, 2016, 2017a, b, 2019). Thus, the production of humic acid from low-quality coal is one of the new focus areas of research to facilitate the value-added products (Tripathi et al. 2009; Das et al. 2013, 2015, 2017; Cheng et al. 2019; Souza and Braganca, 2018). In our earlier studies, we reported the fabrication of humic acid from Cenozoic age high sulphur Northeast region (NER) of Indian coal (Das et al. 2013, 2015, 2017a, b) and their uses as a host material for the synthesis of iron oxide nanocomposite material followed by catalytic application (Das et al. 2017a, b).

In the present investigation, the fabrication of coalbased humic acid is reported and a feasibility study is also reported for application in acid mine drainage (AMD) water treatment and electrochemical devices such as capacitors. Although, humic acid has wide range of applications, but most of the humic is commercially purchased (Yin et al. 2014; Wasiński et al. 2014; Zhu et al. 2015) and the use of coal-based humic acid in AMD water treatment (particularly for Northeast region of India) and electrochemical devices is found to be sparse in the literature.

Acid mine drainage (AMD) is a severe problem created in the high sulfur coalmines around the world including in Northeast region of Indian (Baruah et al. 2010a, b; Chabukdhara and Singh 2016; Dutta et al. 2017, 2018). The mine spoils generated during mining of coals is highly enriched with sulfur and pyrite upon oxidation and hydrolyzing releases acid water (Baruah et al. 2005, 2006; Baruah and Khare 2007, 2010a, 2010b; Chabukdhara and Singh 2016; Dutta et al. 2017, 2018). The AMD waters lower the $\mathrm{pH}$ of the streams, completely kill aquatic lives, increase acidity in the nearby soil during overflow and releases toxic metals at low pH (Baruah et al. 2005, 2006, Baruah and Khare 2007, 2010a, 2010b; Chabukdhara and Singh 2016; Dutta et al. 2017, 2018). Many toxic and heavy elements like V, Cr, Mn, Ni, Cu, Zn, As, Cd, Sb, and $\mathrm{Pb}$ are present in the AMD waters of Northeast India and create adverse environmental effect in the vicinity of collieries (Baruah et al. 2010a, 2010b; Chabukdhara and Singh 2016; Dutta et al. 2017, 2018). The concentration of $\mathrm{Fe}, \mathrm{Mn}, \mathrm{Zn}, \mathrm{Cu}, \mathrm{Ni}$, and $\mathrm{Pb}$ in mine-waters of the Jaintia and Makum coalfields of Northeastern region of India is reported to high as compared to the other mining sites of India (Chabukdhara and Singh 2016).

Therefore, the treatment of AMD water needs attention for removal of toxic heavy metals before the aqueous discharge is allowed to enter streams and water ways. Dowarh et al. (2009) reported the eco-restoration of overburden dumping sites of coal mine area in Tirap collieries, Northeast India to mitigate AMD problems along with the environmental adverse effect. Baruah et al. (2010b) also carried out a pilot plant study for the treatment of AMD water from coalmines of Meghalaya, Northeast India based on the sequential alkaline treatment coupled with biological processing. The nano-mineralogy (Dutta et al. 2017) and physico-chemical analysis of aqueous leaching (Dutta et al. 2018) of the coal, coal-mine overburden, and AMD water from Northeastern coalfield of India was also reported. However, a suitable and adaptable method is still required to mitigate the $\mathrm{AMD}$ problem in the high sulfur coal-mine area of Northeastern region of India.

Therefore, a feasibility study has been made to solve the issues related to the AMD of Northeastern region of India by using coal-derived humic acid since it has an excellent metal complexing ability (Pahlman 1988; Saied et al. 2005; Das et al. 2015) and has been used for waste water treatment by several workers (Liu et al. 2008; Jiang et al. 2014; Li et al. 2011; Tang et al. 2014). The humic acid was reported to be superior for removing of toxic metals such as $\mathrm{Cd}, \mathrm{Hg}$, and $\mathrm{Pb}$ as compared to the $\mathrm{CaO}$ in the $\mathrm{pH}$ range 4-8 (Pahlman 1988). It was found that humic acid metal interaction is $\mathrm{pH}$ dependent and forms chelates more strongly with metals in +2 (II) oxidation state. The reactivity order for metal ion-humic acid chelations is reported to be in the order of $\mathrm{Pb}^{2+}>\mathrm{Cu}^{2+}>\mathrm{Fe}^{2+}>\mathrm{Ni}^{2+}>\mathrm{Zn}^{2+}>$ $\mathrm{Cr}^{3+}$ (Saied et al., 2005).

The present work also describes the electrochemical performance of the coal-derived humic acid with a promising potential for application in the field of electrochemistry (Yin et al. 2014; Wasiński et al. 2014; Zhu et al. 2015). In contrast, the study would make a new path in coal-based carbon materials for using in AMD water treatment and electrochemical devices.

\section{Experimental sections}

\subsection{Coal sample and reagents}

The coal sample from the Northeastern region of India was selected for this study. The raw coal sample (ROM) was manually crushed to below $1 / 8^{\prime \prime}$ sizes and ball milled to powder form $(0.211 \mathrm{~mm}$ sizes $)$. Analytical grade chemical such as $\mathrm{H}_{2} \mathrm{O}_{2}(30 \%), \mathrm{NaOH}, \mathrm{HCl}$, Copper (II) chloride 
dehydrate, and Cadmium chloride were commercially purchased. Polyvinylidene fluoride (PVDF) and N-methyl 2-pyrrolidine (NMP) were also commercially purchased and used for the electrochemical characterization of the coal-derived humic acid. Standard humic acid (Sigma Aldrich) was also commercially purchased and used for the comparative study with the coal-derived humic acid.

\subsection{Chemical and analytical characterizations}

The proximate (moisture, ash content, volatile matter, and fixed carbon) and elemental analyses (carbon, hydrogen, and sulfur) of the raw coal, oxidized coal, and coal-derived humic acid were done by using TGA 701 Thermogravimetric Analyzer, Truspec CHN Macro Determinator, and S-144 DR Sulfur Analyzer as per the standard ASTM D7582-15, ASTM D3176-15, and ASTM D3176-15 methods, respectively. In order to evaluate the thermal stability of the coal-derived humic acid, thermal analyses (non-isothermal) were carried out by using a thermal analyzer (Model: Netzsch STA 449F3) at a heating rate of $5{ }^{\circ} \mathrm{C}$ per min in a nitrogen atmosphere from room temperature to $1000{ }^{\circ} \mathrm{C}$. The UV-Vis (Ultraviolet-visible) spectra were recorded with a UV-Visible Spectrophotometer (UV $1000^{+}$, Lab India). An FTIR spectrometer (SPECTRUM 100, Perkin Elmer, USA) associated with IR software was used to record the Fourier-transform infrared (FT-IR) spectra of the coal-derived humic acid and humic acid-metal complexes by using $\mathrm{KBr}$ pellets with $4 \mathrm{~cm}^{-1}$ spectral resolution. The surface morphology was analyzed by using a field emission-scanning electron microscope (FE-SEM) (ZEISS SIGMA, Carl ZEISS Microscopy, accelerating voltage: $0.5-30 \mathrm{kV}$ ) integrated with an Oxford energy dispersive X-ray spectroscopy (EDS). The SEM images were further developed by "ImageJ" (version 1.47) software.

\subsection{Isolation of humic acid from coal}

The humic acid was isolated from the coal sample as per the method reported in our previous studies (Das et al. 2013, 2015, 2017a, b). Briefly, $100 \mathrm{~g}$ of powder coal samples were oxidized by using $250 \mathrm{~mL}$ hydrogen peroxide $(30 \%)$ in an ice-cold condition. After the exothermic reaction cease, the reaction mixture was cooled to room temperature, filtered, and washed with distilled water until the $\mathrm{pH}$ of the filtrate became neutral. The oven dried oxidized coal samples was then refluxed with $1 \mathrm{~N} \mathrm{NaOH}$ solution for $6 \mathrm{hrs}$ with continuous stirring, cooled to room temperature and kept for overnight. The mixture was then filtered and the alkali soluble portion was collected. The alkali soluble portion was then acidified to $\mathrm{pH} 1-1.5$ by using $6.0 \mathrm{M} \mathrm{HCl}$ and kept overnight in order to precipitate the humic acid. After complete precipitation, the humic acid was collected by centrifugation, purified with dilute $\mathrm{HCl}$ and washed with ultra-pure water until the filtrate became neutral. The final product of humic acid was recovered, freeze dried, and stored for subsequent analysis.

\subsection{Metal-humic acid complex formation study}

The complex formation study was conducted by using $0.1 \%$ (W/V) solution of coal-derived humic acid with metal ions such as Copper $\left(\mathrm{Cu}^{2+}\right)$ and Cadmium $\left(\mathrm{Cd}^{2+}\right) \cdot \mathrm{Cu}^{2+}$ and $\mathrm{Cd}^{2+}$ solutions were prepared from respective Copper (II) chloride dehydrate and Cadmium (II) chloride analytical grade salt, respectively. Both the solution was prepared in $0.1 \mathrm{~N} \mathrm{NaOH}$ and kept for half an hour. The FTIR spectra of the dried precipitates i.e. humic acid-metal complex was recorded and compared with that of the coal-derived humic acid.

\subsection{Treatment of acid mine drainage (AMD) water with coal-derived humic acid}

For these experimental purposes, AMD water were obtained from the Shkentalang point source, Jaintia Hills, Meghalaya and treated with coal-derived humic acid solution. For that purpose, $1 \%(\mathrm{~W} / \mathrm{V})$ and $0.5 \%(\mathrm{~W} / \mathrm{V})$ coal-derived humic acid solution in $0.1 \mathrm{~N} \mathrm{NaOH}$ were prepared. AMD water was treated with coal-derived humic acid solutions (in 4:1 proportions) for four different time periods $(5,60,180 \mathrm{~min}$, and over night). The mixtures were filtered and concentrations of $\mathrm{Zn}, \mathrm{Cu}, \mathrm{Cd}$, and $\mathrm{Pb}$ in all samples were determined by using a Atomic Absorption Spectrometer (Model: A Analyst-700, Make: Perkin Elmer). The $\mathrm{pH}$ of the original AMD water and the humic acid treated AMD water samples were also determined by using a microprocessor-based $\mathrm{pH}$ meter (model 1012E).

\subsection{Electrochemical properties of coal-derived humic acid}

The electrochemical properties of coal-derived humic acid were tested in a electrochemical work station (VSP3 and FlexP0160; BioLogic Science) using three electrode system $(\mathrm{Ag} / \mathrm{AgCl}$ as the reference electrode and Pt-wire as the counter electrode) in order to check the suitability for application in electrochemical devices. The synthesized coal-derived humic acid was coated on a glassy carbon 
electrode and used as working electrode. The slurry of electrode material was prepared by mixing of coal-derived humic acid and polyvinylidene fluoride (PVDF) binder in a ratio of 93:7 and N-Methylpyrrolidone (NMP) as solvent. The slurry was ultrasonicated for approximately six hours for homogenous mixing. Then the slurry was coated on glassy carbon working electrode. In the present investigation, $1 \mathrm{M} \mathrm{H}_{2} \mathrm{SO}_{4}$ was used as an aqueous electrolyte.

\section{Results and discussion}

\subsection{Characterizations of raw coal and isolated coal- derived humic acid}

The physico-chemical properties of the raw coal and isolated humic is summarized in Table 1, which indicates the coal to be of low-ash and high-sulfur in nature. The surface morphology (SEM analysis) of the coal-derived humic acid is found to be not smooth, and flakes sheets are appeared (see Fig. 1a, b), which are mainly composed of carbon (76.05 at.\%) and oxygen (22.67 at.\%) as confirmed from the SEM-EDX analysis (Fig. 1c, d).

In the UV-Vis spectra of coal-derived humic acid (Fig. 2a), the peak observed at around $220-300 \mathrm{~nm}$ is due to the $\pi \rightarrow \pi^{*}$ transition of $\pi$-electron of the aromatic groups present in coal-derived humic acid (Das et al. 2013, 2015, 2017a, b). Similar results were also obtained after recording the UV-Vis spectra of standard humic acid as shown in Fig. 2a. The degree of humification and condensation of aromatic carbon network was also investigated by determining the $\mathrm{E}_{4} / \mathrm{E}_{6}$ ratio $\left(\mathrm{Abs}_{465} / \mathrm{Abs}_{665}\right)$ and $\Delta \log \mathrm{K}\left(\log \mathrm{Abs}_{400}-\log \mathrm{Abs}_{600}\right.$ ) (Campitelli et al. 2006; Das et al. 2015). The $\mathrm{E}_{4} / \mathrm{E}_{6}$ ratio and $\Delta \log \mathrm{K}$ was found to be almost identical for coal-derived humic acid and standard humic acid (Table 2). The $\Delta \log \mathrm{K}$ value of the coal-derived humic acid is found to be $\leq 0.6$, indicating the high degree of humification (Matsui et al. 1984; Das et al. 2015).

The thermal stability of the coal-derived humic acid was evaluated by carrying out the thermogravimetric analysis (TGA) of the sample as shown in Fig. 2b. The weight loss is generally observed with increase of temperature. The initial weight loss $(12.39 \%)$ observed in the range of $30-150{ }^{\circ} \mathrm{C}$ is due to the loss of free moisture (Skhonde et al. 2006, Fong et al. 2007). Between $150-400{ }^{\circ} \mathrm{C}$, weight loss $(17.58 \%)$ is observed due to the decarboxylation reaction and loss of least stable carboxylic acids (Skhonde et al. 2006, Kolokassidou et al. 2007). Between 400-800 ${ }^{\circ} \mathrm{C}$, mass loss (19.39\%) is observed due to the loss of more stable phenolic acids group (Skhonde et al. 2006, Kolokassidou et al. 2007). The conversion of aliphatic C-H group to aromatic $\mathrm{C}-\mathrm{H}$ group takes place at a temperature 200-600 ${ }^{\circ} \mathrm{C}$ (Skhonde et al. 2006, Kolokassidou et al. 2007, $\mathrm{Lu}$ et al. 1997). The maximum weight loss is observed at $286{ }^{\circ} \mathrm{C}$ due to the loss of methyl and other aliphatic groups. The residual mass is found to be $42.55 \%$ at $1000^{\circ} \mathrm{C}$ in nitrogen environment. Thus, the coal-derived humic acid is found to be relatively stable up to about 200 ${ }^{\circ} \mathrm{C}$; above which a mass loss is experienced.

The FTIR spectra of coal-derived humic acid and humic acid-metal complexes provide information on structure, functional groups, and information of modes of complexes. The FTIR spectra were recorded for coal-derived humic acid, standard humic acid, and humic acid-metal complexes $(\mathrm{Cu}$ and $\mathrm{Cd}$ ) (see Fig. 2c-e), and the corresponding peak assignments are summarized in Table 3. The FTIR spectra of coal-derived humic acid is compared with the standard humic acid and found to be similar in nature (Fig. 2c, Table 3) and is also in accordance with the results reported earlier (Das et al. 2015, 2013, 2017a, b). The FTIR intensity within the range of $3000-3500 \mathrm{~cm}^{-1}$ for $\mathrm{Cu}$ - and $\mathrm{Cd}$-humic acid complexes is higher than the coalderived humic acid due to the hydration of water and change in the dipole moment that is caused by change of electronic environment (Erdogan et al. 2007). The absorption band appeared at $1600-1650 \mathrm{~cm}^{-1}$ is due to the $\mathrm{C}=\mathrm{C}, \mathrm{C}=\mathrm{O}$, and $\mathrm{COO}^{-}$group and the intensity is found to be increased for metal-humic acid complexes (Cu-humic acid and Cd-humic acid) because of the formation of complexes between metal ion with the functional group as well as change in dipole moment the functional group (Erdogan et al. 2007). The two new bands appeared at 1187 $\mathrm{cm}^{-1}$ and $1111 \mathrm{~cm}^{-1}$ due to formation of complex structure between carboxylic acid group of the coal-derived humic acid and metal ions $(\mathrm{Cu}$ and $\mathrm{Cd})$. The carboxylic

Table 1 Physico-chemical properties of the raw coal and isolated humic acid (wt\%)

\begin{tabular}{|c|c|c|c|c|c|c|c|}
\hline \multirow[t]{2}{*}{ Sample studied } & \multicolumn{4}{|c|}{ Proximate analysis (\%) } & \multicolumn{2}{|c|}{$\begin{array}{l}\text { Ultimate analysis } \\
(\%)\end{array}$} & \multirow[t]{2}{*}{ Total Sulfur $(\%)$} \\
\hline & Moisture & Ash content & Volatile Matter & Fixed Carbon (by difference) & Carbon & Hydrogen & \\
\hline Raw coal & 6.00 & 3.00 & 40.50 & 50.50 & 76.00 & 5.85 & 5.21 \\
\hline Oxidised coal & 6.15 & 2.00 & 43.36 & 48.49 & 73.00 & 5.62 & 3.62 \\
\hline Coal-derived humic acid & 9.00 & 1.50 & 46.00 & 43.50 & 70.00 & 5.50 & 3.54 \\
\hline
\end{tabular}



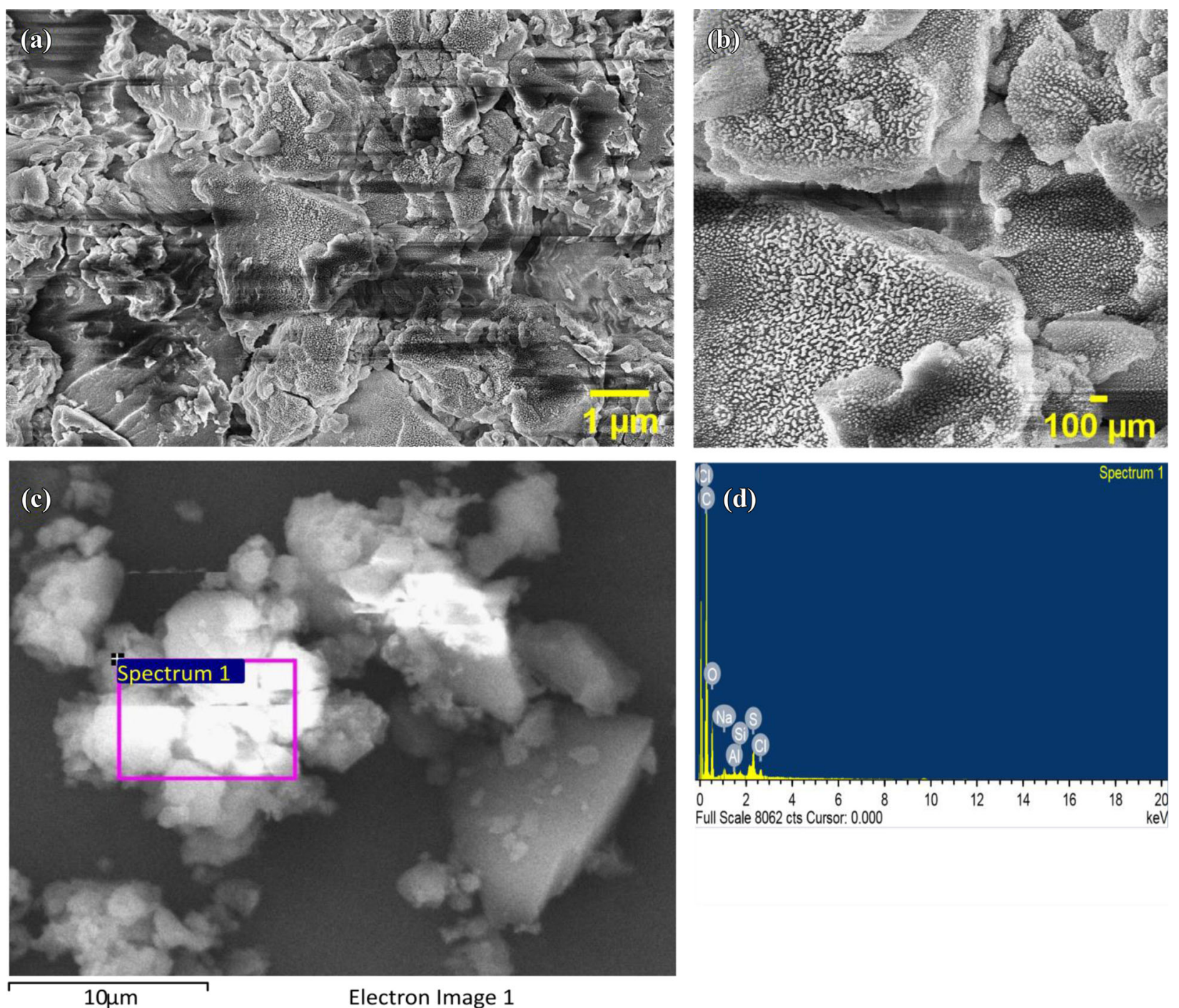

Fig. 1 a, b SEM analysis of coal-derived humic acid, c, d SEM-EDX of coal-derived humic acid

acid groups of coal-derived humic acid may take part in the complex formation via both ionic and non-ionic bonding (Baruah 1982; Steelink 2002), while salicylic acid type chelates may be formed by the metal ions with the $\mathrm{OH}$ groups where both the carboxyl and phenolic groups are involved (Baruah 1982).

The physico-chemical, UV-Vis, and FTIR studies revealed the formation of humic acid from coal. The FTIR study indicates the formation of metal-humic acid complex.

\subsection{AMD water treatment by using coal-derived humic acid}

The extent of metal removal by coal-derived humic acid from AMD water sample is found to be independent of time as shown in Fig. 2f. The removal of metal from AMD water by using coal-derived humic acid found to be in the order of $\mathrm{Pb}>\mathrm{Cu}>\mathrm{Zn}>\mathrm{Cd}$ (Fig. 2f) (Saied et al. 2005). But the extent of removal of Lead $(\mathrm{Pb})$ increases more after 60 minutes when treated with $1 \%$ coal-derived humic acid solution. The $\mathrm{pH}$ of AMD water is found to be increased after treatment with coal-derived humic acid (see Table 4). A mechanism of isolation of humic acid from coal and their use for AMD water treatment is depicted in Fig. 3.

\subsection{Formation mechanism and main control factors of humic acid}

Humic acids consist of a mixture of weak aliphatic carbon chains and aromatic carbon rings, which are not soluble in water under acidic conditions but are soluble in water under alkaline conditions. In the coalification process, plant debris is first converted into humic substances and progressively humic substances are converted to peat, lignite, brown coal, bituminous coal, and finally into anthracite 
(a)

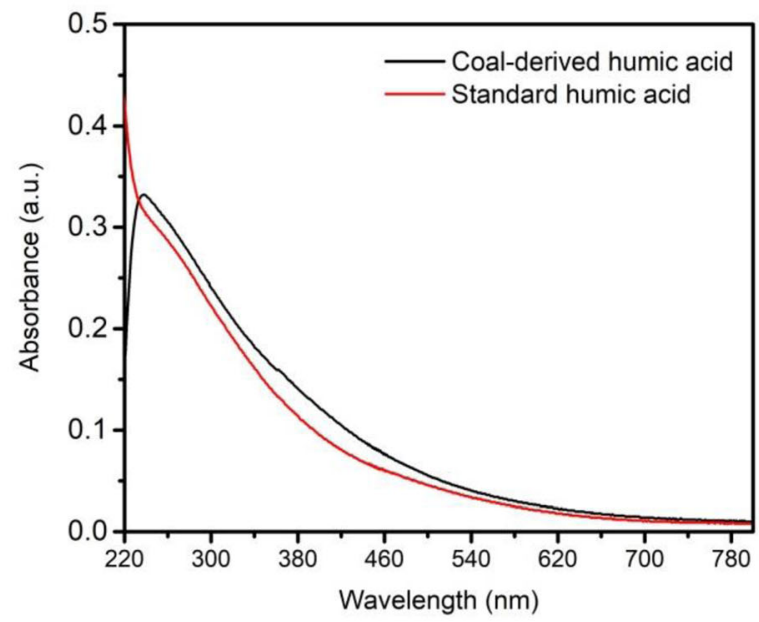

(c)

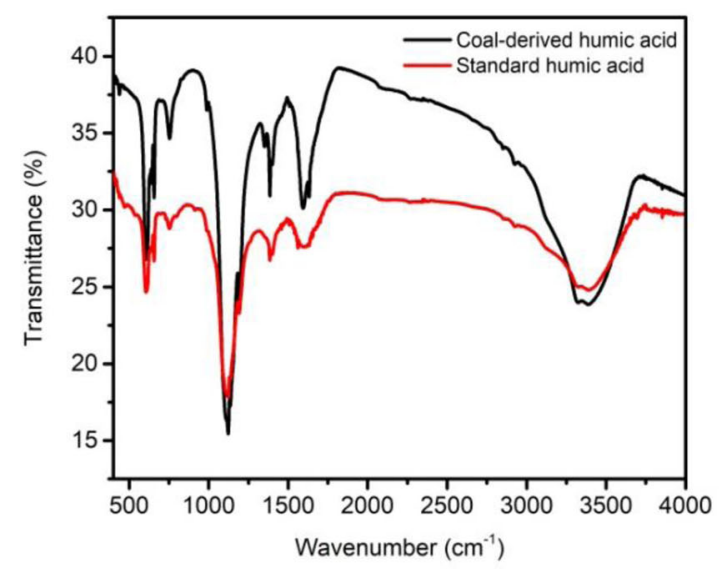

(e)

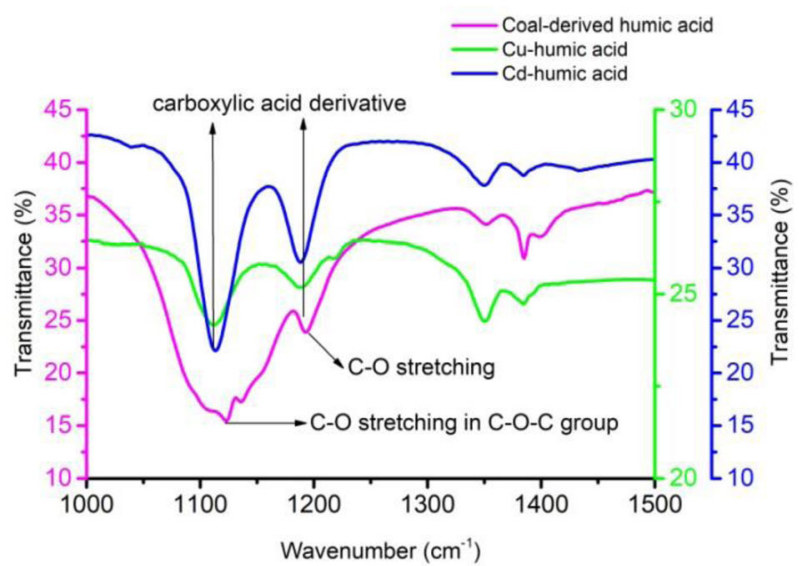

(b)

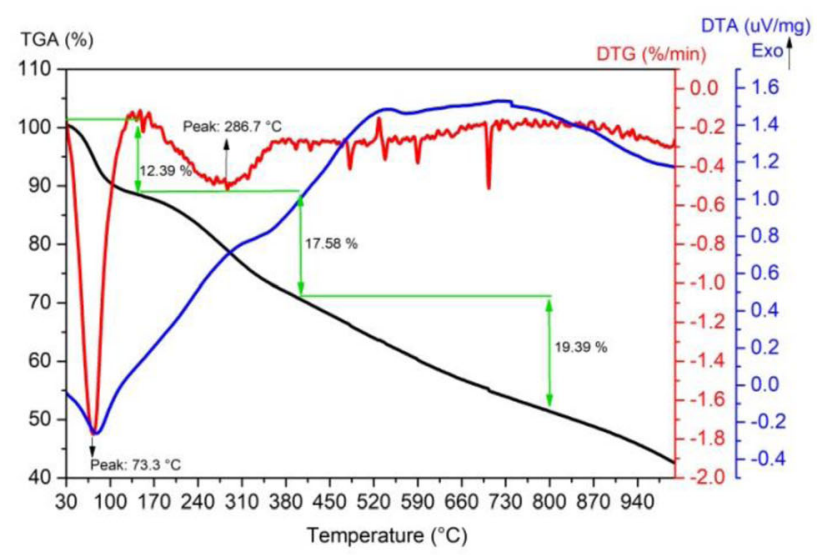

(d)

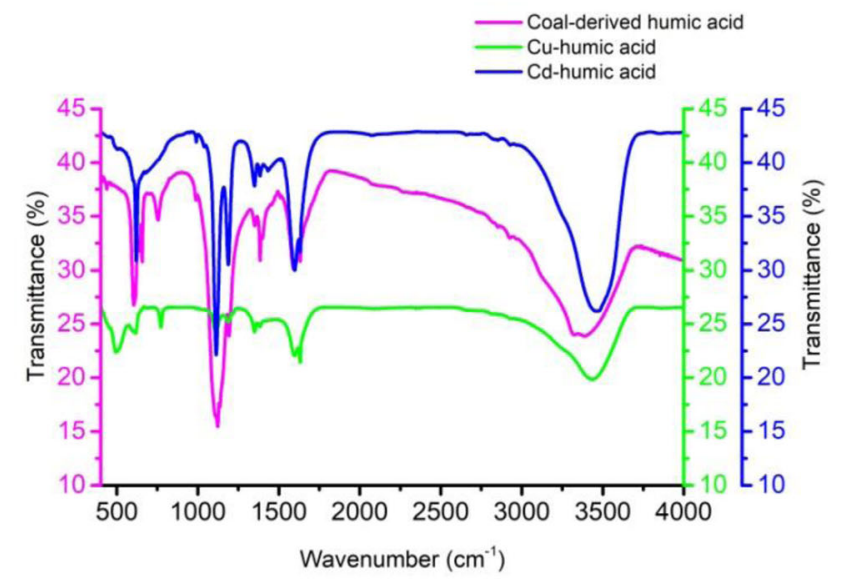

(f)

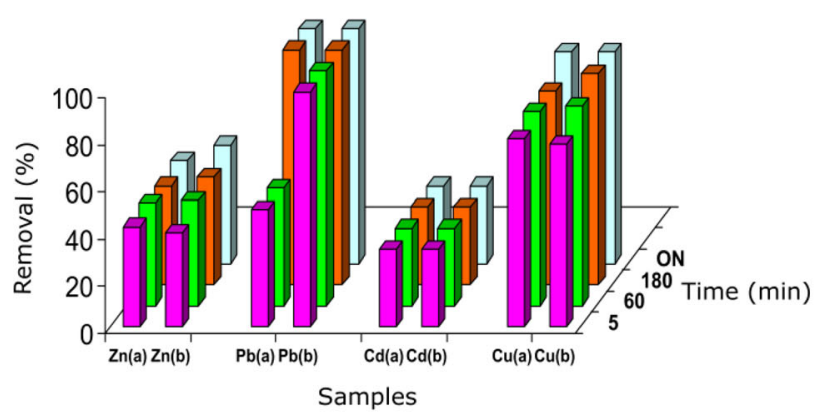

(a) treated with $1 \%$ coal-derived humic acid solution

(b) treated with $0.5 \%$ coal-derived humic acid solution

Fig. 2 a UV-visible spectra of coal-derived humic acid and standard humic acid, b thermal analysis of coal-derived humic acid, $\mathbf{c}$ FTIR spectra of coal-derived humic acid and standard humic acid, $\mathbf{d}$ FTIR spectra of coal-derived humic acid and its metal complex with Cu (II) and Cd (II) ions, e FTIR spectra of coal-derived humic acid and its metal complex with $\mathrm{Cu}$ (II) and Cd (II) ions in the range of $1000-1500 \mathrm{~cm}^{-1}$, $\mathbf{f}$ removal of metals from AMD water by coal-derived humic acid 
Table 2 UV-visible spectroscopic data

\begin{tabular}{lll}
\hline Sample & $\mathrm{E}_{4} / \mathrm{E}_{6}$ ratio $\left(\mathrm{Abs}_{465} / \mathrm{Abs}_{665}\right)$ & $\Delta \log \mathrm{K}\left(\log \mathrm{Abs}_{400}-\log \mathrm{Abs}_{600}\right)$ \\
\hline Coal-derived humic acid & 4.75 & 0.667 \\
Standard humic acid & 4.67 & 0.675 \\
\hline
\end{tabular}

coal by condensation followed by diagenesis process (van Krevelen 1961; Stach et al. 1982; O'Keefe et al. 2013; Dai et al. 2020). During the coalification process, the oxygen content as $-\mathrm{COOH}$ decreases, and that as $-\mathrm{OH}$ increases relatively. Thus, the low-quality coals are much more suitable than high-quality coals for the extraction of humic acid (Cheng et al. 2019). In the present study, the subbituminous Cenozoic-age coal sample was selected from the Northeastern region of India. Oxidation of coal in presence of hydrogen peroxide destroyed the macromolecular structure of coal, leading to the breakage and deformation of weak chemical bonds and alkyl structure, the reduction of relative molecular mass, and increases the content of oxygen-containing functional groups (Fig. 3). The addition of $\mathrm{NaOH}$ also destroyed the chelating forces between humic acid and metal ions present in oxidized coal samples and solubilized the humic acid (Fig. 3). The alkaline soluble portion, which contains humic acid is separated from the humin portion (alkaline insoluble portion) via the filtration process. In an acidic medium, the hydrogen $\left(\mathrm{H}^{+}\right)$is bound to the surface functional groups of the humic acid. Due to these protonation phenomena of humic acid in an acidic medium, humic acid became hydrophobic and formed a micelle-like structure (Cheng et al. 2019; Souza and Braganca, 2018). The micelle-like structures completely expel the water around the humic acid molecules at $\mathrm{pH} 1-1.5$ and as a result, the humic acid became insoluble and precipitates. The rank/grade of coal samples, sizes of the coal particles (small size coal particles increase the contact between the alkali and coal samples and leads to the enhancement in the humic acid yield), reaction conditions (temperature and time), and amount of alkali and $\mathrm{pH}$ at acidic medium are the main control factors for the production of humic acid.

\subsection{Electrochemical properties of coal-derived humic acid}

\subsubsection{Cyclic voltammetry study}

The cyclic voltammetry (CV) analysis was carried out to evaluate the oxidation-reduction behavior of coal-derived humic acid. CV analysis was done at different scan rates $(10 \mathrm{mV} / \mathrm{s}, 20 \mathrm{mV} / \mathrm{s}, 50 \mathrm{mV} / \mathrm{s}$, and $100 \mathrm{mV} / \mathrm{s})$ in the potential range of -0.2 to $0.2 \mathrm{~V}$. Leaf-like structures were obtained, and oxidation-reduction peaks were found to be absent as shown in Fig. 4a. The absence of redox peaks revealed that electrochemical rate of charge and discharge is pseudo-constant over entire voltammetry cycles (Yang et al. 2012). The electrode material was observed to have a stable capacitive process as the curve is symmetric (Fig. 4a) (Gu et al. 2016) and showed electrical double layer capacitor properties. The specific capacitance $\left(\mathrm{C}_{\mathrm{sp}}\right)$ of the coal-derived humic acid was calculated by using the following Eq. (1):

$\mathrm{C}_{\mathrm{sp}}=\frac{\int I(E) d E}{m \times \Delta V \times v}$

where, ' $\int I(E) d E$ ' is the area of the CV curve, ' $\mathrm{m}$ ' is the mass ( $\mathrm{g}$ ) of the coated material, $\Delta V$ is the potential range $(\mathrm{V})$ and $v$ is the scan rate. The specific capacitance is found to be $7,4,2$, and $1 \mathrm{mF} / \mathrm{g}$ in the scan rates of $10,20,50$, and $100 \mathrm{mV} / \mathrm{s}$, respectively. The specific capacitance is found to be decrease as the scan rate increases, which may be due to the fact that the higher scan rates do not allow enough time for the ions to diffuse into the pores and less available surface area is used (Cao et al. 2018).

\subsubsection{Chronopotentiometry (CP)}

The charge storage performance and stability of the coalderived humic acid after several charge and discharge cycles were studied by using chronopotentiometry (CP) analysis (Fig. 4b, c). CP was performed in the potential range of -0.2 to 0.2 for 1000 cycles and found to be stable. The curve was found to be symmetric and linear and the quick current voltage response indicated good electrochemical performance. The linear curve with constant slopes over the total range of potential is observed (Shabeeba et al. 2018). The specific capacitance is determined by using the following equation:

$C_{\mathrm{sp}}=\frac{I d t}{m \times \Delta V}$

where ' $I$ ' is the discharge current (A), ' $d t$ ' is the discharge time (s), $\Delta V$ is working potential window (V), and $m$ signifies mass ( $\mathrm{g}$ ) of active electrode. The specific capacitance is found to be $22 \mathrm{mF} / \mathrm{g}$. 
Table 3 Major infrared absorption bands $\left(\mathrm{cm}^{-1}\right)$ for coal-derived humic acid, standard humic acid, and its metal complexes

\begin{tabular}{|c|c|c|c|c|}
\hline Sample & Absorption bands $\left(\mathrm{cm}^{-1}\right)$ & Intensity & Assignment & Functional class \\
\hline \multirow[t]{11}{*}{ Coal-derived humic acid } & 3391(br) & Broad & $\mathrm{O}-\mathrm{H}$ stretching (H-bonded) & Alcoholic/phenolic \\
\hline & $1619(\mathrm{~m})$ & Medium & $\mathrm{C}=\mathrm{C}, \mathrm{C}=\mathrm{O}, \mathrm{COO}^{-}$ & Amines/carboxylic acid \\
\hline & & & $\mathrm{NH}_{2}$ scissoring (1-amines) & \\
\hline & 1401(w) & Weak & $\mathrm{C}-\mathrm{O}-\mathrm{H}$ bending & Carboxylic acid/derivatives \\
\hline & 1384(w) & Weak & $\mathrm{O}-\mathrm{H}$ bending in plane & Alcohols/phenols \\
\hline & $1350(w)$ & Weak & $\mathrm{O}-\mathrm{H}$ bending in plane & Alcohols/phenols \\
\hline & 1191(w) & Weak & $\mathrm{C}-\mathrm{O}$ stretching & Alcohols/phenols \\
\hline & $1122(s)$ & Strong & $\mathrm{C}-\mathrm{O}$ stretching in $\mathrm{C}-\mathrm{O}-\mathrm{C}$ group & Alcohols/phenols \\
\hline & 753(w) & Weak & $\mathrm{O}-\mathrm{H}$ bend (out-of-plane) & Alcohols/phenols \\
\hline & $656(w)$ & Weak & $\mathrm{O}-\mathrm{H}$ bend (out-of-plane) & Alcohols/phenols \\
\hline & $604(\mathrm{~s})$ & Strong & $\mathrm{C}-\mathrm{H}$ deformation & Alkynes \\
\hline \multirow[t]{11}{*}{ Standard humic acid } & 3391(br) & Broad & $\mathrm{O}-\mathrm{H}$ stretching (H-bonded) & Alcoholic/Phenolic, \\
\hline & $1619(\mathrm{~m})$ & Medium & $\mathrm{C}=\mathrm{C}, \mathrm{C}=\mathrm{O}, \mathrm{COO}^{-}$ & Amines/Carboxylic acid \\
\hline & & & $\mathrm{NH}_{2}$ scissoring (1-amines) & \\
\hline & 1401(w) & Weak & $\mathrm{C}-\mathrm{O}-\mathrm{H}$ bending & Carboxylic acid/derivatives \\
\hline & $1384(w)$ & Weak & $\mathrm{O}-\mathrm{H}$ bending in plane & Alcohols/phenols \\
\hline & $1350(w)$ & Weak & $\mathrm{O}-\mathrm{H}$ bending in plane & Alcohols/phenols \\
\hline & 1191(w) & Weak & $\mathrm{C}-\mathrm{O}$ stretching & Alcohols/phenols \\
\hline & $1122(\mathrm{~s})$ & Strong & $\mathrm{C}-\mathrm{O}$ stretching in $\mathrm{C}-\mathrm{O}-\mathrm{C}$ group & Alcohols/phenols \\
\hline & 753(w) & Weak & $\mathrm{O}-\mathrm{H}$ bend (out-of-plane) & Alcohols/phenols \\
\hline & $656(w)$ & Weak & O-H bend (out-of-plane) & Alcohols/phenols \\
\hline & $604(s)$ & Strong & $\mathrm{C}-\mathrm{H}$ deformation & Alkynes \\
\hline \multirow[t]{11}{*}{ Cu-humic acid } & 3436(br) & Broad & O-H stretching (H-bonded) & Alcoholic/Phenolic, \\
\hline & $1632(s)$ & Strong & $\mathrm{C}=\mathrm{C}, \mathrm{C}=\mathrm{O}, \mathrm{COO}^{-}$ & Amines/carboxylic acid \\
\hline & & & $\mathrm{NH}_{2}$ scissoring (1-amines) & \\
\hline & $1560(s)$ & Strong & Carboxylates (salts) or amino acid Zwitterious & Carboxylic acid/derivatives \\
\hline & $1383(w)$ & Weak & $\mathrm{O}-\mathrm{H}$ bending in plane & Alcohols/phenols \\
\hline & $1350(w)$ & Weak & $\mathrm{O}-\mathrm{H}$ bending in plane & Alcohols/phenols \\
\hline & 1187(w) & Weak & Carboxylic acid derivative & Carboxylic acid/derivatives \\
\hline & $1111(\mathrm{~s})$ & Strong & Carboxylic acid derivative & Carboxylic acid/derivatives \\
\hline & $771(\mathrm{~s})$ & Strong & $\mathrm{C}-\mathrm{H}$ bending and ring pukering & \\
\hline & $616(w)$ & Weak & $\mathrm{C}-\mathrm{H}$ deformation & Alkynes \\
\hline & $493(\mathrm{~s})$ & Strong & & Clay minerals \\
\hline \multirow[t]{10}{*}{ Cd-humic acid } & 3465(br) & Broad & O-H stretching (H-bonded) & Alcoholic/Phenolic, \\
\hline & $1630(w)$ & Weak & $\mathrm{C}=\mathrm{C}, \mathrm{C}=\mathrm{O}, \mathrm{COO}^{-}$ & Amines/Carboxylic acid \\
\hline & & & $\mathrm{NH}_{2}$ scissoring (1-amines) & \\
\hline & $1560(s)$ & Strong & Carboxylates (salts) or amino acid Zwitterious & Carboxylic acid/derivatives \\
\hline & 1432(w) & Weak & $\mathrm{C}-\mathrm{O}-\mathrm{H}$ bending & Carboxylic acid/derivatives \\
\hline & $1384(w)$ & Weak & $\mathrm{O}-\mathrm{H}$ bending in plane & Alcohols/phenols \\
\hline & $1350(w)$ & Weak & $\mathrm{O}-\mathrm{H}$ bending in plane & Alcohols/phenols \\
\hline & $1187(\mathrm{~s})$ & Strong & Carboxylic acid derivative & Carboxylic acid/derivatives \\
\hline & $1111(\mathrm{~s})$ & Strong & Carboxylic acid derivative & Carboxylic acid/derivatives \\
\hline & $619(\mathrm{~s})$ & Strong & $\mathrm{C}-\mathrm{H}$ deformation & Alkynes \\
\hline
\end{tabular}


Table $4 \mathrm{pH}$ of original AMD water and coal-derived humic acid treated AMD water samples

\begin{tabular}{llll}
\hline Time of treatment & Original AMD water & \multicolumn{2}{l}{ Treated with } \\
\cline { 3 - 4 } & & $1 \%$ humic acid & $0.5 \%$ humic acid \\
\hline $5 \mathrm{~min}$ & 1.97 & 4.08 & 4.49 \\
$60 \mathrm{~min}$ & & 4.13 & 4.20 \\
$180 \mathrm{~min}$ & & 4.03 & 4.31 \\
Over night & & 4.06 & 4.53 \\
\hline
\end{tabular}

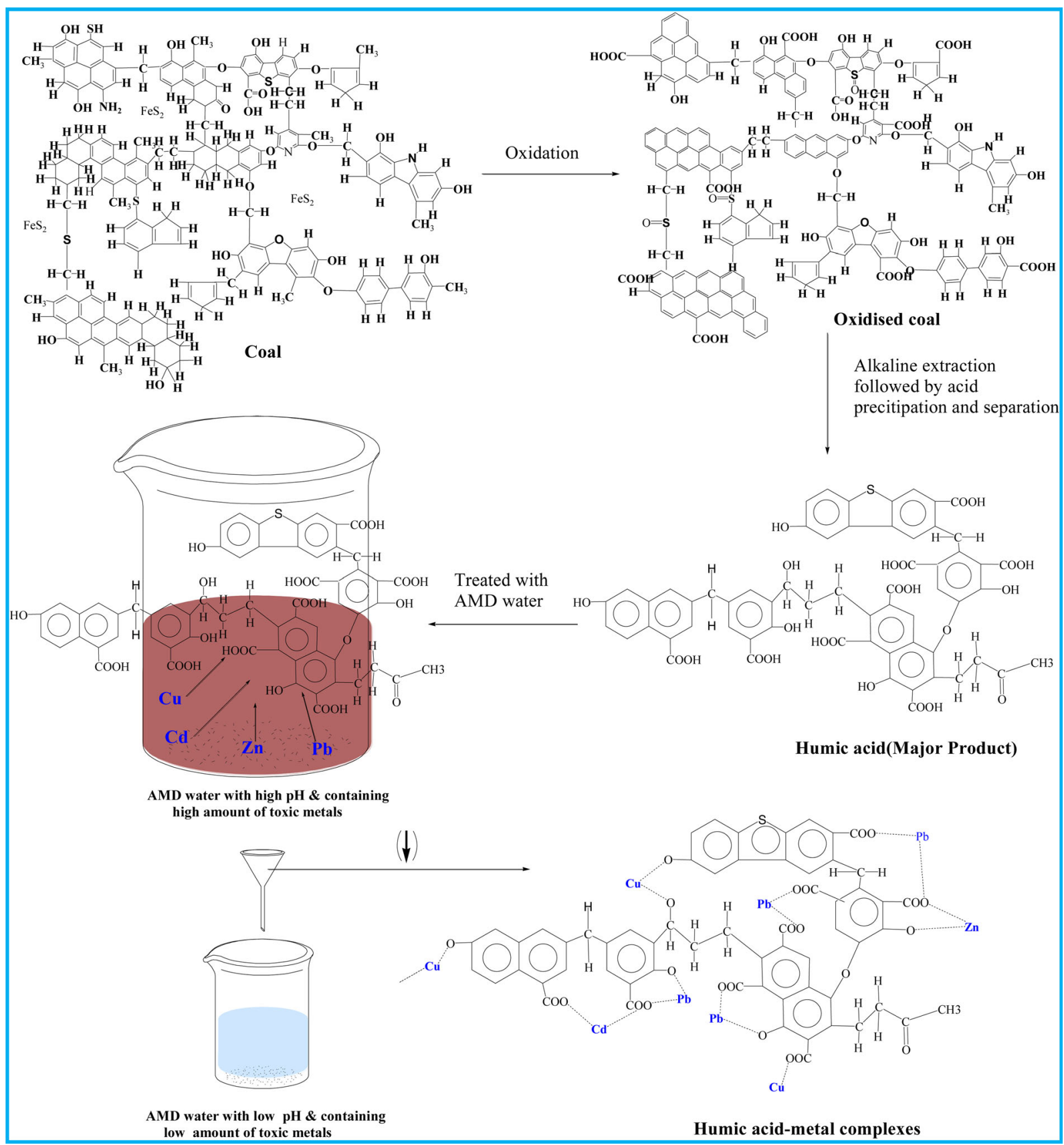

Fig. 3 Plausible mechanism of isolation of humic acid from coal and use for the AMD water treatment 

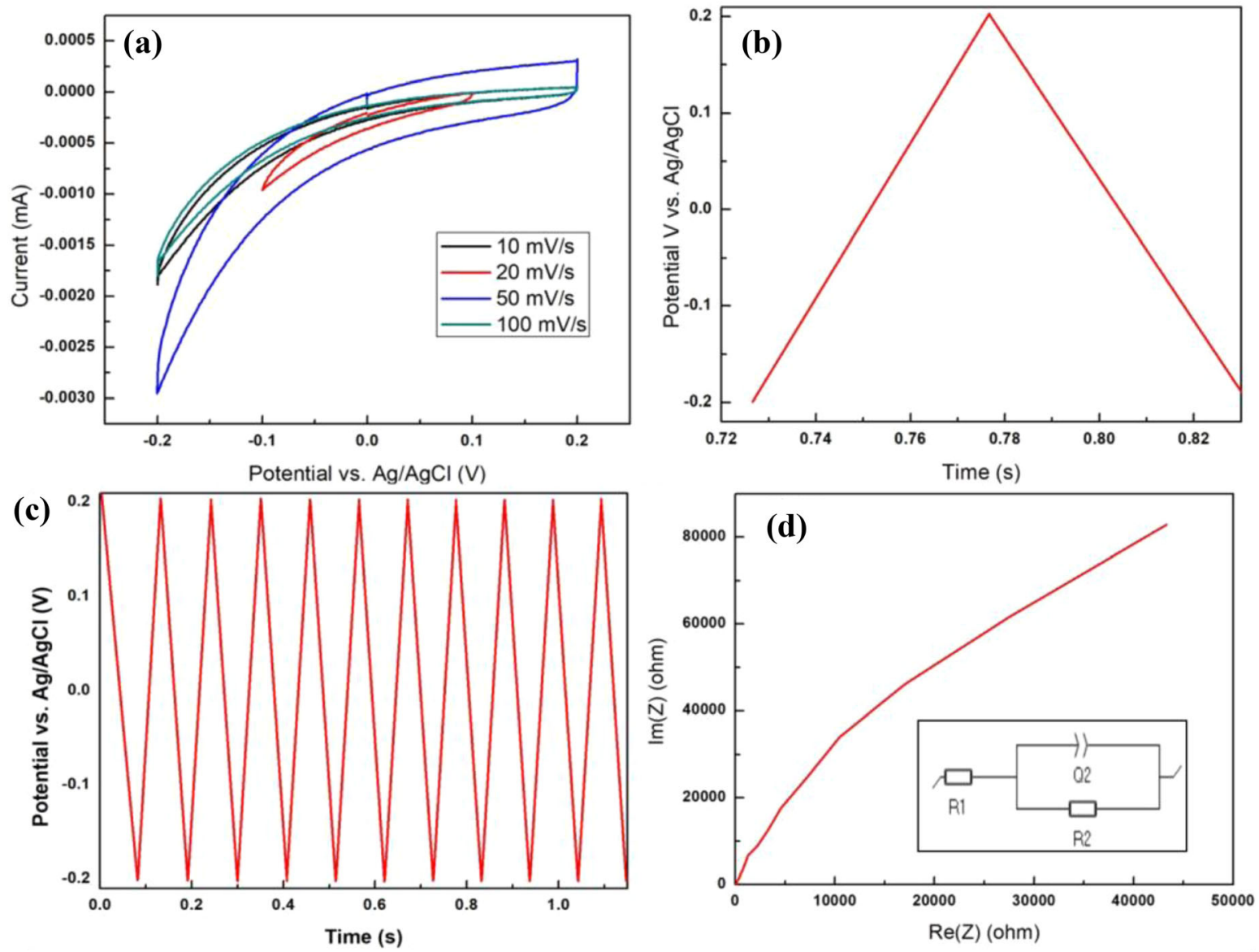

Fig. 4 Electrochemical performance of coal-derived humic acid in three-electrode system in $1 \mathrm{M} \mathrm{H}_{2} \mathrm{SO}_{4}$. a Cyclic voltammetry at different scan rate 10, 20, 50, and $100 \mathrm{mV} / \mathrm{s}$ respectively; b, c Chronopotentiometry (CP), d Potentio Electrochemical Impedance Spectroscopy (PEIS) with Nyquist plot and equivalent circuit

\subsubsection{Potentio-electrochemical impedance spectroscopy (PEIS)}

PEIS measurement was done in the frequency range 100 $\mathrm{mHz}$ to $100 \mathrm{kHz}$ and data is plotted as Nyquist diagram. The Fig. $4 \mathrm{~d}$ shows a half semicircular curve which can be explained by presence of surface passive layer. The equivalent circuit of Nyquist plot is plotted by using Biologic software associated with the equipment. In the circuit, $\mathrm{R} 1$ is electrolyte resistance, $\mathrm{Q}$ is the double layer electrical capacity and R2 is charge transfer resistance (Dimitrijević et al. 2019). R1 is found to be $8.32 \Omega$ and $\mathrm{R} 2$ is $324 \mathrm{k} \Omega$, and $\mathrm{Q}$ is $3.6 \mathrm{microF} / \mathrm{s}$. The deviation from an ideal semicircle was attributed to the frequency dispersion and the inhomogeneity of the passive layer surface (Liu et al. 2018).

The electrochemical properties of the coal-derived humic acid can be improved by the use of suitable activating agents in the synthesis process and with the addition of additives in the electrode material. The energy density and power density can be improved by using organic electrolyte and hence by increasing the potential window.
In order to improve the conductive properties of the material, great attention has to be given in the electrode fabrication process in the future.

\section{Conclusions}

This study leads to the conclusion that humic acid can be easily isolated from inferior quality coals of the Northeastern region of India. The amount of isolation of humic acid from coal depends upon the rank/grade of the coals. The coals having low ash, high carbon content, high oxygen-containing functional groups are suitable for isolation of humic acid. The product developed meets the standards laid down by the International Humic Substances Society (IHSS). The isolated coal-derived humic acid is found to be effective in removing toxic metals like $\mathrm{Cu}, \mathrm{Cd}, \mathrm{Pb}$ and $\mathrm{Zn}$ from AMD water samples leading to the management of AMD. Moreover, the $\mathrm{pH}$ of the AMD water is also found to increase by the addition of coal-derived humic acid solution indicating their suitability for use in the treatment of 
acidic water, reclamation of acidic soil, and as a metal detoxification agent for various purposes. The complex formation ability of coal-derived humic acid also promotes retention and accumulation of heavy metal and may also play a vital role in the agricultural sectors as a soil conditioner. Moreover, the coal-derived humic acid possesses optimizable electrochemical properties and promising specific capacitance of $7 \mathrm{mF} / \mathrm{g}$ at scan rate $10 \mathrm{mV} / \mathrm{s}$ (cyclic voltammetry analysis) and $22 \mathrm{mF} / \mathrm{g}$ with cycling stability over 1000 cycles within the potential window $0.4 \mathrm{~V}$ (charge-discharge analysis). The optimizable and easily processable coal-derived humic acid can be used as a lowcost, environmentally friendly, and non-toxic carbon electrode material for electrochemical capacitors.

Acknowledgements Authors are very much thankful to the Director of CSIR-NEIST, Jorhat for encouragement and CSIR, New Delhi for financial support (OLP-2031) to carry out the work. The authors are also very much thankful to Dr. Ponchami Sharma for her assistance during the samples collections and analysis and Dr. Jugal Bori for assistance in electron beam analysis of the samples. Authors express thanks to Dr. Jim Hower for his comments and English corrections.

Open Access This article is licensed under a Creative Commons Attribution 4.0 International License, which permits use, sharing, adaptation, distribution and reproduction in any medium or format, as long as you give appropriate credit to the original author(s) and the source, provide a link to the Creative Commons licence, and indicate if changes were made. The images or other third party material in this article are included in the article's Creative Commons licence, unless indicated otherwise in a credit line to the material. If material is not included in the article's Creative Commons licence and your intended use is not permitted by statutory regulation or exceeds the permitted use, you will need to obtain permission directly from the copyright holder. To view a copy of this licence, visit http://creativecommons. org/licenses/by/4.0/.

\section{References}

ASTM D7582-15 (2015) Standard test methods for proximate analysis of coal and coke by macro thermogravimetric analysis. ASTM International, West Conshohocken. www.astm.org

ASTM D3176-15 (2015) Standard practice for ultimate analysis of coal and coke. ASTM International, West Conshohocken. www. astm.org

Baruah BP, Khare P (2007) Desulfurization of oxidized Indian coals with solvent extraction and alkali treatment. Energy Fuels 21(4):2156-2164

Baruah BP, Khare P (2010a) Mobility of trace and heavy elements in environmental from high sulfur Indian coal mines. Appl Geochem 25:1621-1631

Baruah BP, Saikia BK, Kotoky P, Rao PG (2006) Aqueous leaching of high sulfur sub-bituminous coals in Assam, India. Energy Fuels 20:1550-1555

Baruah BP, Khare P, Rao PG (2010b) Management of acid mine drainage (AMD) in Indian coal mines In: Proceedings of international seminar on mineral processing technology (MPT2010), pp 1163-1170

Baruah BP, Kotoky P, Rao PG (2005) Genesis of acid mine drainage from coalfields of Assam, India. In: Proceedings of international seminar on coal science and technology-emerging global dimensions: global coal. Allied Publishers. ISBN: 81-7764818-7

Baruah MK (1982) Organogeochemical aspects of the formation of pyrite and organic sulphur in coal. Ph.D. thesis, Gauhati University

Cao J, Wang Y, Chen C, Yu F, Ma J (2018) A Comparison of graphene hydrogels modified with single-walled/multiwalled carbon nanotubes as electrode materials for capacitive deionization. J Colloid Interface Sci 518:69-75

Chabukdhara M, Singh OP (2016) Coal mining in northeast India: an overview of environmental issues and treatment approaches. Int J Coal Sci Technol 3(2):87-96

Cheng G, Niu Z, Zhang C, Zhang X, Li X (2019) Extraction of humic acid from lignite by KOH-hydrothermal method. Appl Sci 9:1356

Dai S, Bechtel A, Eble CF, Flores RM, French D, Graham IT, Hood MM, Hower JC, Korasidis VA, Moore TA, Püttmann W, Wei Q, O'Keefe JMK (2020) Recognition of peat depositional environments in coal: a review. Int J Coal Geol 219:103383. https://doi. org/10.1016/j.coal.2019.103383

Das T, Boruah PK, Das MR, Saikia BK (2016) Formation of onionlike fullerene and chemically converted graphene-like nanosheets from low-quality coals: application in photocatalytic degradation of 2-nitrophenol. RSC Adv 6(42):35177-35190

Das T, Chauhan H, Deka S, Chaudhary S, Boruah R, Saikia BK (2017a) Promising carbon nanosheet-based supercapacitor electrode materials from low-grade coals. Microporous Mesoporous Mater 253:80-90

Das T, Kalita G, Bora PJ, Prajapati D, Baishya G, Saikia BK (2017) Humi-Fe3O4 nanocomposites from low-quality coal with amazing catalytic performance in reduction of nitrophenols. J Environ Chem Eng 5(2):1855-1865

Das T, Saikia BK (2017) Nanodiamonds produced from lowgrade Indian coals. ACS Sustain Chem Eng 5(11):9619-9624

Das T, Saikia BK, Baruah BP (2013) Feasibility studies for isolation of humic acid from coal of Mongchen Coalfield, Nagaland. J Indian Chem Soc 90(11):2007-2014

Das T, Saikia BK, Baruah BP (2016) Formation of carbon nano-balls and carbon nano-tubes from northeast Indian Tertiary coal: value added products from low grade coal. Gondwana Res 31:295-304

Das T, Saikia BK, Baruah BP, Das D (2015) Characterizations of humic acid isolated from coals of two nagaland coalfields of India in relation to their origin. J Geol Soc India 86:468-474

Das T, Saikia BK, Dekaboruah HP, Bordoloi M, Neog D, Bora JJ, Lahkar J, Narzary B, Roy S, Ramaiah D (2019) Blue-fluorescent and biocompatible carbon dots derived from abundant lowquality coals. J Photochem Photobiol B 195:1-11

Dekker J, Cronje IJ, Louwrens HB, Swart H (1990) Noncatalytic oxidation of water slurried coal with oxygen: a promising new route to oxihumic and oxifulvic acids. In: Proceedings of the seventh annual international coal conference. University of Pittsburgh, Pittsburgh, PA, pp 703-708

Dimitrijević VD, Stanković MN, Đorđević DM, Krstić IM, Nikolić MG, Bojić AL, Krstić NS (2019) The preliminary adsorption investigation of urtica dioica L. biomass material as a potential biosorbent for heavy metal ions. SubChem 64(1): 19-39

Duraia EM, Beall GW (2015a) Humidity sensing properties of reduced humic acid. Sens Actuators B 220:22-26

Duraia EM, Henderson B, Beall GW (2015b) Reduced humic acid nano sheets and its uses as nanofiller. J Phys Chem Solids 85:86-90

Dutta M, Khare P, Chakravarty S, Saikia D, Saikia BK (2018) Physico-chemical and elemental investigation of aqueous leaching of high sulfur coal and mine overburden from Ledo coalfield of Northeast India. Int J Coal Sci Technol 5(3):265-281 
Dutta M, Saikia J, Taffarel SR, Waanders FB, Medeiros DD, Cutruneo CMNL, Silva LFO, Saikia BK (2017) Environmental assessment and nano-mineralogical characterization of coal, overburden and sediment from Indian coal mining acid drainage. Geosci Front 8(6):1285-1297

Erdogan S, Bayasal A, Akba O, Hamamci C (2007) Interaction of Metals with acid isolated from oxidized coal. Pol J Environ Stud 16(5):671-675

Fong SS, Seng L, Majri NB, Mat HB (2007) A comparative evaluation on the oxidative approaches for extraction of humic acids from low rank coal of Mukah, Sarawak. J Braz Chem Soc 18(1):34-40

Janos P, Kozler J (1995) Thermal stability of humic acid and some of their derivatives. Fuel 981:111-119

Jiang W, Cai Q, Xu W, Yang M, Cai Y, Dionysious DD, O'Shea KE (2014) $\mathrm{Cr}(\mathrm{VI})$ adsorption and reduction by humic acid coated on magnetite. Environ Sci Technol 48(14):8078-8085

Kolokassidou C, Pashalidis I, Costa CN, Efstathiou AM, Buckau G (2007) Thermal stability of solid and aqueous solution of humic acid. Thermochim Acta 454(2):78-83

Kurkova M, Klika Z, Klikova C, Havel J (2004) Humic acids from oxidized coals I. Elemental composition, titration curves, heavy metals in HA samples, nuclear magnetic resonance spectra of HAs and infrared spectroscopy. Chemosphere 54:1237-1245

Li Q, Sun L, Zhang Y, Qian Y, Zhai J (2011) Characteristics of equilibrium, kinetics studies for adsorption of $\mathrm{Hg}(\mathrm{II})$ and $\mathrm{Cr}(\mathrm{VI})$ by polyaniline/Humic acid composite. Desalination 266:188-194

Liu Q, Li H, Jin G, Zheng WL (2018) Assessing the influence of humic acids on the weathering of galena and its environmental implications. Ecotoxicol Environ Saf 158:230-238

Liu JF, Zhao ZS, Jiang GB (2008) Coating $\mathrm{Fe}_{3} \mathrm{O}_{4}$ magnetic nanoparticles with Humic acid for high efficient removal of heavy metals in water. Environ Sci Technol 42(18):6949-6954

Lu XQ, Vassallo AM, Jhonson WD (1997) Thermal stability of humic substances and their metal forms: an investigation using FTIR emission Spectroscopy. J Anal Appl Pyrol 43(2):103-113

Niu H, Zhang D, Zhang S, Zhang X, Meng Z, Cai Y (2011) Humic acid coated $\mathrm{Fe}_{3} \mathrm{O}_{4}$ magnetic nanoparticles as highly efficient Fenton-like catalyst for complete mineralization of sulfathiazole. J Hazard Mater 190:559-565

O'Keefe JMK, Bechtel A, Christanis K, Dai S, DiMichele WA, Eble CF, Esterle JS, Mastalerz M, Raymond AL, Valentim BV, Wagner NJ, Ward CR, Hower JC (2013) On the fundamental difference between coal rank and coal type. Int $\mathrm{J}$ Coal Geol 118:58-87

Pahlman JE, Khalafalla SE (1988) Report of investigation: use of lignochemicals and humic acids to remove heavy metals from process waste stream, Bureau of Mines, United States Department of The Interior, $p 1$

Peng L, Qin P, Lei M, Zeng Q, Song H, Yang J, Shao J, Liao B, Gu J (2012) Modifying $\mathrm{Fe}_{3} \mathrm{O}_{4}$ nanoparticles with Humic acid for removal of Rhodamine $B$ in water. J Hazard Mater 209-210:193-198

Powell C, Beall GW (2015) Graphene oxide and graphene from low grade coal: Synthesis, characterization and applications. Curr Opin Colloid Interface Sci 20(5-6):362-366

Rousa R, Girardi E, Calemma V (1994) Humic acids from coal. Production, characterization, and utilization. Elsevier, Amsterdam, pp 1225-1244

Saied S, Siddique A, Mumtaz M, Ali K (2005) Study of the heavy metal pollution treatment potential of the coal generated humic acid. J Basic Appl Sci 1(2):625-689

Saikia M, Hower JC, Das T, Dutta T, Saikia BK (2019) Feasibility study of preparation of carbon quantum dots from Pennsylvania anthracite and Kentucky bituminous coals. Fuel 243(1):433-440
Shabeeba P, Thayyil MS, Pillai MP, Soufeena PP, Niveditha CV (2018) Electrochemical investigation of activated carbon electrode supercapacitors. Russ J Electrochem 54:349-356

Skhonde MP, Herod AA, van der Walt TJ, Tsatsi WL, Mokoena K (2006) The effect of thermal treatment on the compositional structure of humic acids extracted from south Africa bituminous coal. Int J Miner Process 81(1):51-57

Souza FD, Braganca SR (2018) Extraction and characterization of humic acid from coal for the application as dispersant of ceramic powders. J Mater Res Technol 7(3):254-260

Stach E, Mackowesky M, Teichmuller M, Taylor GCD, Teichmuller R (1982) Stach's textbook of coal petrology, 3rd edn. Gebruder Borntraeger, Berlin

Steelink C (2002) Investigating humic acids in soils. Anal Chem 74(11):326A-333A

Stevenson FJ (1994) Humus chemistry: genesis, compositions, reactions, vol 2. Wiley, New York, pp 188-211

Tang Y, Yang Y, Cheng D, Gao B, Wan Y, Li YC (2017) Valueadded humic acid derived from lignite using novel solid-phase activation process with $\mathrm{Pd} / \mathrm{CeO} 2$ nanocatalyst: a physiochemical study. ACS Sustain Chem Eng 5(11):10099-10110

Tang WW, Zeng GM, Gong JL, Liang J, Xu P, Zhang C, Huang BB (2014) Impact of humic/fulvic acid on the removal of heavy metals from aqueous solutions using nanomaterials: a review. Sci Total Environ 468-469:1014-1027

Tripathi RC, Jain VK, Tripathi PSM (2009) Fungal biosolubilization of Neyveli lignite into humic acid. Energy Sour A Recov Utilization Environ Eff 32(1):72-82

van Krevelen DW (1961) Coal: typology-chemistry-physics-constitution. Elsevier, Amsterdam

Wang CF, Fan X, Zhang F, Wang SZ, Zhao YP, Zhao XY, Zhao W, Zhu TG, Lu JL, Wei XY (2017) Characterization of humic acids extracted from a lignite and interpretation for the mass spectra. RSC Adv 7(33):20677-20684

Wasiński K, Walkowiak M, Lota G (2014) Humic acids as pseudo capacitive electrolyte additive for electrochemical double layer capacitors. J Power Sources 255:230-234

Xiao L, Li Y, Liao Y, Ma H, Wu J, Zhang Y, Yao J (2018) Bioconversion of lignite humic acid by white-rot fungi and characterization of products. 3 Biotech 8(5):258

Yang L, Cheng S, Ding Y, Zhu X, Wang ZL, Liu M (2012) Hierarchical network architectures of carbon fiber paper supported cobalt oxide nanonet for high-capacity pseudocapacitors. Nano Lett 12:321-325

Yin J, Zhang D, Zhao J, Wang X, Zhu H, Wang C (2014) Meso- and micro-porous composite carbons derived from Humic acid for supercapacitors. Electrochim Acta 136:504-512

Zhang X, Zhang P, Wu Z, Zhang L, Zeng G, Zhou C (2013) Adsorption of methylene blue onto Humic acid-coated $\mathrm{Fe}_{3} \mathrm{O}_{4}$ nanoparticles. Colloids Surf A Physicochem Eng Asp 435:85-90

Zhou C, Wu Z, Zhang W, Xia M, Zeng G, Zou B, Zhang P (2011) Facile synthesis of humic acid-coated iron oxide nanoparticles and their applications in wastewater treatment. Funct Mater Lett 4:373-376

Zhu H, Yin J, Zhao X, Wang C, Yang X (2015) Humic acid as promising organic anodes for lithium/sodium ion batteries. Chem Commun 51:14708-14711

\section{Publisher's Note}

Springer Nature remains neutral with regard to jurisdictional claims in published maps and institutional affiliations. 